\title{
CURRENT VIEWS ON THE PATHOGENESIS OF COMMON "STROKES"
}

\author{
F. J. FAwCETt, M.B., M.R.C.P. \\ Lecturer in Pathology
}

University of Birmingham

W. Thomas Smith, M.D., M.C.Path. Reader in Neuropathology
THE TITLE of this review is deliberately provocative and only becomes meaningful when the term "stroke" is defined. According to "A New English Dictionary" (Murray, 1919) a "stroke" is "an apoplectic or ..... paralytic seizure"; apoplexy is described as "a malady .... . usually caused by an effusion of blood or serum in the brain .....". The survey will be arbitrarily restrioted to current views on pathological aspects of commoner seizures classifiable as apoplectic by the above definition. "Effusions of blood" undoubtedly means cerebral haemorrhage, and "effusions of serum" would seem to refer to forms of cerebral infarction such as acute colliquation or more chronic encystation ("apoplectic cyst"). "Paralytic seizures" due to other causes are thus outside our self-imposed terms of reference. The account will be further limited by confining it to the three varieties of apoplectic stroke that have attracted most attention in recent years. These are: cerebral infarction related to atheromatous disease of the intracranial and/or carotid and vertebral arteries; subarachnoid haemorrhage and other consequences of ruptured berry ("congenital") aneurysm of the circle of Willis; and massive intracerebral bleeding associated with systemic arterial hypertension. Infarction resulting from unusual forms of arterial disease or from emboli of cardiac origin, and bleeding due to haemorrhagic disorders, trauma, tumours etc. are therefore not included.

\section{Cerebral Infarction}

Historical

Though Morgagni (1761) distinguished between cerebral haemorrhage ("sanguineous stroke") and cerebral softening ("'non-sanguineous stroke") many years elapsed before the cause of infarction was suspected. Abercrombie (1828) defined its ischaemic nature and held that the effects of local arterial lesions and of extracranial factors were important. Through-

Based on a joint communication presented at a Symposium on Cerebro-vascular Disease, organised by the Board of Graduate Studies of the Faculty of Medicine, University of Birmingham, on June 26th, 1965. out the 19th and early 20th centuries it was widely held that cerebral infarcts were simply explained by occlusion of the supplying artery, this belief being reinforced by Cohnheim's description in 1872 of clearly defined vascular territories and by the belief in end-arteries. The role of anastomotic channels was seldom considered. The clinical and pathological features of occlusion of all main arteries were carefully documented and many tantalizing syndromes, beloved of examiners, were attributed to occlusion of specific branches of the oircle of Willis. Occasional dissenters such as Nothnagel (1877) noted that relevant arteries were not always occluded in brains showing infarction. The possibility of resorption of thrombus and the concept of reactive vasospasm to explain these discrepancies were neither generally accepted nor confirmed.

The importance of the carotid arteries haso long been known and the word carotid is an adaptation of the Greek term for "to stupefy"; Galen showed that carotid compression could cause "carus" or insensibility. Todd (1844), Gull (1855) and Ramsay Hunt (1914) recognised the importance of carotid occlusion in the pathogenesis of cerebral infarction but the knowledge that bilateral occlusion was consistent with survival and that carotid ligation was not necessarily associated with cerebral lesions temporarily discredited the former avant-garde observations. The advent of arteriography in the 1930's stimulated considerable interest in internal carotid artery thrombosis, the clinical syndrome first being reported by Moniz, Lima and de Lacerda (1937). However, it was only recently that the carotid and vertebral systems together with the circle of Willis were considered as an integral unit in a detailed clinical and pathological investigation by Hutchinson and Yates (1957) and Yates and Hutchinson (1961).

\section{The role of carotico-vertebral stenosis}

Yates and Hutchinson fully investigated 100 cases in which the clinical picture suggested that cerebral ischaemia had either caused or contributed to death; cases recognised as intra- 
cranial haemorrhage or cerebral embolism complicating heart disease were excluded. They examined the whole cerebrovascular system, including the carotid and vertebral arteries and circle of Willis, together with the brain. Because of the technical difficulties involved in removing the intraosseous and intracranial parts of the vertebral and internal carotid arteries at necropsy this procedure had been neglected in previous work on cerebral infarction. The impressive results of Hutchinson and Yates showed that atheromatous diseases of the extracranial arteries is of paramount significance in the pathogenesis of cerebral ischaemia and infarction. They found occlusion and/or serious stenosis of one or more neck arteries in 58 of the 100 cases; in 18 only the carotids and in 7 only the vertebrals were affected but in 33 both were affected. In 35 cases there were in all 74 separate infarcts; all but 3 of these 35 cases showed significant stenosis (defined as $50 \%$ or more reduction of lumen) or ocolusion of the extracranial arteries; only 19 of these same cases (showing 22 of the infarcts) were associated with significant changes in the intracranial arteries. Thus, in $16(46 \%)$ of the cases with infarcts significant disease of the intracranial arteries was excluded. The site of the disease in the internal carotid arteries was most commonly the carotid sinus. In the vertebral arteries atherosclerosis was somewhat more widespread but also tended to involve the proximal $2 \mathrm{~cm}$. In 19 cases showing thrombotic occlusion of one or more extracranial arteries all but 4 showed cerebral infarction, and 2 of these almost certainly died before gross changes had time to develop.

Yates and Hutchinson noted that distortion and obstruction of diseased vertebral arteries could be produced or aggravated by osteoarthritis of the cervical spine as subsequently appraised by Brain (1963). They also emphasised the role of general systemic factors such as anaemia and blood loss, anoxia, hypotension and traumatic shock, and concluded that cerebral infarction rarely had a single cause; it was usually the result of a combination of systemic disease and inadequacy of total cerebral blood-flow due to stenosis or occlusion of extracranial or intracranial cerebral arteries, or both, infarction being commoner with extracranial than intracranial arteriopathy. They further suggested that atheroma of the carotid sinus could cause intermittent hypotension by affecting the carotid reflex mechanism, and that vasospasm of the major extracranial cerebral arteries was sometimes induced by arterial disease; both of these effects could bring about temporary disturbances of cerebral function, especially when associated with sludging of blood in the capillary bed. These conclusion were in general supported by the findings of McGee, McPhedran and Hoffman (1962); Baker, Dahl and Sandler (1963); and Fisher, Gore, Okabe and White (1965).

The significance of non-occlusive stenosis in reducing blood-flow has been questioned by Mitchell and Schwartz (1965) on the grounds that the series of Hutchinson and Yates (1957), selected because of clinical evidence of cerebral ischaemia, did not show a significantly different prevalence of carotico-vertebral stenosis from that found in their own entirely unselected necropsy series. Amongst 93 adults over the age of 35 only 27 had clinical evidence of "strokes". They found stenoses at some point along the vessels in $90 \%$ of men and $85 \%$ of women which were severe in $43 \%$ of men and $35 \%$ of women. Furthermore, severe narrowings were present in the carotid sinus in one man in 7 and in the vertebral arteries in one man in 4. Mitchell and Schwartz commented that $90 \%$ of the peripheral resistance in the cerebral circulation is contributed by the smaller intracranial vessels and considerable reduction in the calibre of the major neck arteries can occur before their narrowing becomes a controlling factor in brain blood-flow. They argued that their own findings showed the relation between carotico-vertebral stenosis and "strokes" to be uncertain and suggested that the stenosed segments do not usually seriously impair blood-flow but are more important as a source of emboli which block the smaller cerebral vessels. They also claimed that as the frequency of "strokes" and of caroticovertebral stenosis are both correlated with age, it is inevitable that there will be a correlation between them, even if causally unrelated. It is unfortunate that Mitchell and Schwartz neither specified the variety of "stroke" to which they alluded, nor described whether cerebral infarction, massive haemorrhage or other lesions were found post mortem in the small number of cases on which they based their conclusions; they also ignored the more detailed report of Yates and Hutchinson (1961). The role of cervical artery stenosis in massive haemorrhagic strokes could be of paradoxical significance, and even protect the brain against the damaging effects of hypertension; the demonstration by Wilson and Byrom (1939) that hypertension induced experimentally by controlled stenosis of a renal artery does not 
result in homolateral renal vascular lesions, is of interest in this respect. It is a common experience that any group of cases diagnosed on clinical grounds as "cerebral infarction" will include a number of unexpected "haemorrhages", neoplasms etc. and in Yates and Hutchinson's cases of "cerebral ischaemia", from which clinically confirmed haemorrhages were excluded, necropsy showed haemorrhages in $28 \%$ and neoplasms in $6 \%$. Though data concerning the terminal neurological state and the appearances of the brains at necropsy were not given, it is probable that some of Mitchell and Schwartz's patients dying from general medical diseases such as cardiac or respiratory failure, cancer etc. did in fact succumb to cerebral disorder resulting from the combination of carotico-vertebral stenosis and adverse haemodynamic effects brought about by these general diseases. This is a common mode of death in hospital practice and often explains why other patients with similar diseases, admitted to hospital for similar reasons, respond favourably to appropriate treatment.

Gunning, Pickening, Robb-Smith and RossRussell (1964) found that friable emboli, composed of fused platelet masses detached from mural thrombi in the internal carotid artery, and possibly other sites, were the commonest cause for intermittent attacks of blindness and contralateral hemiparesis; the commonest cause for intermittent attacks of blindness or hemiparesis; and a possible cause for a single attack of monocular blindness or hemiparesis. These authors also discussed four possible effects of mural thrombi in the internal carotid arteries: emboli may become detached, impact at a branch of appropriate size, break up if sufficiently friable in consistency, reimpact in smaller distal branches, and perhaps repeat this process several times till they ultimately disappear; they may cause permanent embolic blockage of cerebral or retinal anteries; they may remain in situ and become organised and incorporated into the artery wall; and they may propagate and eventually occlude the whole internal carotid artery and perhaps even its anterior and middle cerebral branches.

Important observations on the haemodynamic effects of carotid artery stenosis have recently been made by Brice, Dowsett and Lowe (1965) on a series of patients undergoing carotid ligation for the treatment of berry aneurysms. The dimensions of an antificial constriction which just produced a detectable change of pressure gradient and flow in the internal carotid artery were determined under local anaesthesia.
It was concluded that a stenosis will significantly reduce blood-flow if its cross-sectional area is less than $2 \mathrm{sq}$. $\mathrm{mm}$. If the minimal area is more than 5 sq. mm. blood-flow will not be reduced. Between 2 and 5 sq. $\mathrm{mm}$. blood-flow may possibly be reduced, depending on the shape, length and number of stenoses. These observations suggest that the lumen of the internal carotid artery can be narrowed to less than $2 \mathrm{~mm}$. diameter before flow is reduced appreciably. Pathological assessments of arterial stenoses (as recommended by the World Health Organization) usually classify reduced lumen diameters of $50 \%$ or more as "severe", whereas the stenosis that Brice and others (1965) regard as possibly significant (2-5 sq. mm.) corresponds to a reduction of the order of $84-93 \%$. If this is correct, many of the stenoses classified by Yates and Hutchinson and by Mitchell and Schwartz as severe, probably had negligible effect on resistance; this inference reinforces the suggestion that the significance of stenotic segments in the cervical carotico-vertebral arteries may be related to embolus formation rather than reduction of blood-flow by coarctation.

\section{The result of carotico-vertebral occlusion}

Whilst there is therefore some douht as to the precise role of neck-artery stenosis in the causation of cerebral infarction, the importance of thrombotic occlusion is unquestionable. Mitchell and Schwartz found occlusion in 19\% of their 27 patients with clinical evidence of "strokes" and Yates and Hutchinson in 19 of their 100 cases of cerebral ischaemia, and $43 \%$ of their 35 cases with macroscopical infarction of the brain. Carotico-vertebral occlusion, however, can occur in patients who have shown neither clinical evidence of cerebral ischaemia nor necropsy evidence of infarction (Rob, 1961; Roberts, 1965). Agenesis of an internal carotid artery may also be found without related lesions in extreme old age (Turnbull, 1962). In such cases the development of adequate anastomotic channels is the determining factor: these are derived from the meningeal anastomoses on the surface of the brain between all of the major arteries (vander Eecken and Adams, 1953); the circle of Willis (Hutchinson, 1962); and the anastomoses between the internal and external carotid arteries (Weiss, 1938). Collaterals develop much more effectively if the occlusion is gradual rather than sudden. The functional capacity of the circle of Willis may be impaired by disease or by anomalies such as aplasia or hypoplasia; the latter occur in at least $40 \%$ of all individuals (Alpers and 
Berry, 1963; Riggs and Rupp, 1963), though their true significance in association with neckartery disease remains to be determined. It is therefore probable that carotico-vertebral occlusion is most likely to cause cerebral infarction when emboli are detached, when thrombus is propagated into the anterior and middle cerebral or basilar arteries, or when the other cervical arteries or circle of Willis are severely diseased or show a significant developmental anomaly such as aplasia of an important segment.

Mitchell and Schwartz found that neck artery lesions tend to be bilateral and occlusion is frequently associated with stenosis on the contralateral side and Hutchinson and Yates emphasised that if one of the carotid or vertebral vessels is involved there is approximately an $80 \%$ chance that one of the remaining vessels will also be affected. Not only does this prejudice the development of adequate collateral circulation but it also makes it difficult to relate the site of vascular changes to the distribution of brain lesions. Carotid artery occlusion usually results in infarction in the middle cerebral artery distribution while vertebral occlusion usually results in brainstem and hind-brain infarction (Yates and Hutchinson). When there is combined caroticovertebral stenosis the junctional territories will be most vulnerable to consequential ischaemia, whatever the cause. Dickinson (1961) found that the site of extracranial stenosis or occlusion had little effect on the localisation of cerebral damage and that disproportionate arterial involvement on one side was just as likely to cause infarction in the contralateral as in the homolateral hemisphere. A corollary to these observations is that it is probable that cerebral ischaemia due to carotico-vertebral disease might be treated effectively by improving the blood-carrying capacity of any of the four major neck-vessels, irrespective of their apparent relation to the location of cerebral changes. Evidence supporting this view is found in recent papers by De Bakey, Crawford and Fields (1961) and Humphries, Young, Beven, Le Fevre and de Wolfe (1965).

\section{The importance of haemodynamic crises}

Because of the variable distribution and severity of carotico-vertebral and intracranial atherosclerosis, and the anastomotic vagaries of a transformed cerebral oirculation brought on by stenosis and/or occlusion, recurrent and transient attacks of carotid and particularly vertebro-basilar ischaemia (Marshall. 1964; Williams, 1964) can occur when the delicate balance is prejudiced by episodic haemodynamic crises as suggested by Denny-Brown (1951).

Disequilibrium is precipitated by a wide range of systemic disorders such as heart disease, haemorrhage, anaemia, anoxic anoxia, traumatic or surgical shock, medical or surgical hypotensive therapy, altered water/electrolyte balance (with dehydration, diuretic therapy etc.), as well as by local factors such as vertebral artery compression by osteoarthritic spurs during movement of the head and neck (especially rotation and extension), or transient vascular occlusion due to progressive fragmentation and ultimate dissolution of fragile microemboli, as previously noted. In the recently described subclavian-steal syndrome, reviewed by Toole (1964) and Patel and Toole (1965) stenosis or occlusion of the first part of the subclavian or innominate artery causes reversal of blood-flow in the vertebral artery; haemodynamic crises occur when blood is temporarily shunted from the vertebro-basilar territory (brain-stem, cerebellum, hindbrain and inner ear), and the resultant ischaemia induces transient disturbances such as vertigo, weakness of the limbs, visual upsets, ophthalmoplegia, ataxia etc. Preciplitating factors include head or homolateral upper limb movements and postural hypotension.

The rising incidence of cerebral infarction

Yates (1964) showed that during the previous five years cerebral infarction had become a commoner form of "stroke" than cerebral haemorrhage, though in the 1930's haemorrhage was three times as frequent. This change in pattern was apparently due to a gradual fall in deaths from haemorrhage and an abrupt rise in cerebral infarction between 1947 and 1955. The evidence was adduced from the Registrar General's overall statistics for deaths, and confirmed by comparison with the necropsy findings on 3,397 "strokes". The incidence of fatal cerebral haemorrhage in men and women was the same at almost all ages. Cerebral infarction has always been commoner in men than women of the same age and the incidence in women increases with age parallel to that of men but with a constant lag of up to two years. Age and cohort analysis of the available statistics showed an apparent reduction of cerebral infarction, similar in all age groups at risk, during 1940-1945, the years of the war. It was suggested that this was due to suppression of certain complications of atherosclerosis - possibly thrombosis-by a rapidly acting unknown factor either introduced or removed in the war years; this factor was probably a dietetic 
restriction (such as fats or sugar) rather than increased physical activity, as the less active elderly benefited as much as the more active younger cohorts.

Subarachnoid Haemorrhage, and Other Consequences of Ruptured Berry ("Congenital") Aneurysm of the Circle of Willis.

The aetiology of cerebral aneurysms

Though the main recent interest of pathologists in this problem has been in the nature and mechanism of the cerebral lesions that commonly complicate subarachnoid haemorrhage, the aetiology of the responsible berry aneurysm is still in doubt. Medial defects at bifurcations of the cerebral anteries in man (Forbus, 1930; Glynn, 1940; Stehbens, 1959) and animals (Stehbens, 1963a) are very common, but their role in the development of human aneurysms has been questioned (Glynn, 1940; Stehbens, 1959), and comparable aneurysms in animals are almost unknown (Stehbens, 1963a). Similar medial defects in the media of extracranial arteries of man (Forbus) and animals (Stehbens, 1963a) are not associated with aneurysm formation. Glynn concluded that medial defects played no part in the development of berry aneurysms as their occurrence in $80 \%$ of cerebral bifurcations does not furnish a satisfactory explanation of a lesion found in less than $10 \%$ of all subjects; he demonstrated experimentally the importance of the internal elastic lamella in maintaining the form of the cerebral arteries and ascribed aneurysms to degeneration of elastica. Richardson and Hyland (1941) thought that the medial defect determined the site of some aneurysms but that an additional acquired lesion played an essential part in their formation. Carmichael (1950) held that aneurysms always arose at the site of substantial defects in the muscle and elastic coats and that while developmental deficiency was mainly responsible for the muscle lesions, degenerative processes, mainly of atheromatous type, caused changes in the elastica; the chance occurrence of elastic and muscle defects of adequate size probably explained the low incidence of aneurysms. Crawford (1959) reached similar conclusions but stressed the additional role of high blood pressure. Stehbens ( $1963 \mathrm{~b}$ and c) thought that berry aneurysms were probably acquired. He concluded that there was a distination between the small "congenital" medial defects (of Forbus) which occur in the foetus and infant as well as adults, and the larger early aneurysmal changes (described by
Carmichael) which only occur in adults. Small defects were numerous, increased in frequency with age, occurred throughout the circle of Willis and were prevalent in the lateral angle and apex of birfurcations; large defects were infrequent, uncommon in the posterior half of the circle of Willis, only occurred at the apex of bifurcations where aneurysms were found, and were less abruptly demarcated from the normal adjacent media. The age distribution of aneurysms - mean age 50.2 years, only $22.5 \%$ occurring under the age of 40 years, very few under the age of 20 years-favoured an acquired origin. Stehbens also reported that developmental anomalies of the cerebral arteries were no more frequent in association with aneurysms.

\section{The consequences of rupture}

The main consequences of ruptured berry aneurysms are subarachnoid and intracerebral haemorrhages and cerebral infarction. The appearance of diffuse haemorrhage within the subarachnoid space is well known, adequately described in standard textbooks and presents no problems. Little factual information has been available until recently however, on the intracerebral complications of ruptured aneurysms.

\section{Intracerebral haematoma}

Intracerebral haematoma may be the result of secondary rupture of a localised subarachnoid haematoma situated in a large fissure (most commonly interfrontal with aneurysms of the anterior communicating or anterior cerebral arteries, or Sylvian with middle cerebral aneurysms) or of direct rupture of an aneurysm into the brain, particularly when the sac is adherent to or buried in the brain substance. Tomlinson (1959) and Crompton (1962) showed that: anterior communicating and anterior cerebral aneurysms were most commonly associated with intracerebral haematomas in the frontal lobes, the cavity of the septum pellucidum or the white-matter of the corpus callosum; middle cerebral aneurysms usually resulted in haematomas in the region of the external capsule and less commonly in the frontal or temporal lobes; posterior communicating aneurysms frequently ruptured into the temporal lobes; and aneurysms at the terminal bifurcation of the internal carotid were often embedded in and ruptured directly into the frontal lobes. Intracerebral rupture of aneurysms can mimic massive hypertensive haemorrhage and the pathological diagnosis may necessitate careful study to establish a correct diagnosis. Robertson (1949) noted that recurrent haemorrhages from 
aneurysms were more likely to give rise to intracerebral rupture. Crompton (1962) found that recurrent haemorrhages were also more commonly associated with ventricular dilatation following intracerebral or intraventricular rupture, possibly as the result of secondary arachnoidal adhesions obliterating the exit foramina of the 4th ventricle. Intracerebral haematoma is more likely to be associated with fatal coma than is uncomplicated subarachnoid bleeding and examination of the brains of patients who have survived previous haemorrhage(s) rarely shows evidence of old haematomas.

\section{Cerebral infarction}

The incidence of cerebral infarction following the rupture of cerebral aneurysms is undoubtedly high; recent figures are $55 \%$ overall (Schneck,1964) and 80\% of women and 69\% of men (Crompton, 1964a). In the past, infarction has often been overlooked because it is often difficult to distinguish macroscopically and is often eclipsed by the more dramatic appearance of subarachnoid or intracerebral haematomas. The lesions are patchy, pale or rarely haemorrhagic in colour; they may be abundant, and though usually most numerous in the territory of the aneurysmbearing artery, also occur throughout the brain, even in the opposite hemisphere. The greymatter of the cerebral cortex and basal ganglia and to a lesser extent the central white-matter are affected to a variable extent; the cerebellum and brain-stem are rarely involved. Histologically the lesions show variable ischaemic changes, depending on the availability of anastomotic circulation; the degree of phagocytic infiltration and reactive gliosis is correlated with the survival period and patients dying from recurrent haemorrhage months or years after a previous episode may show marked gliotic scarring. "Oedematous" swelling of the central white-matter is commonly associated with the infarcts and is probably an important factor in elevating the intracranial pressure and impairing blood-flow, so perpetuating a vicious circle of raised pressure; hippocampal, cingulate and/or tonsillar herniations are frequently seen. The infarcts do not appear to be due to microthrombosis.

\section{The cause of infarction}

The mechanism of infarction has been discussed by Tomlinson (1959), Barbara Smith (1963), Crompton (1964b) and Schneck who found a positive relationship to factors such as the presence of large subarachnoid haematomas, angiographic vascular spasm or narrowing, recent surgical intervention, systemic hypotension and atheroma or anomalies of the circle of Willis; these factors are rarely associated with comparable infarction in the absence of aneurysm.

Haematomas are important because the vessels traversing them show changes such as kinking and compression, mural oedema, thrombosis and necrosis; blood may also track along the perivascular sheaths of basal perforating arteries and impair the blood supply to basal ganglia.

The existence and significance of cerebrovascular spasm has been frequently discussed. There seems no doubt from experimental evidence (Raynor and McMurtry, 1963; Corday and other's, 1963), angiographic evidence (du $\vec{N}$ Boulay, 1963; Allcock and Drake, 1965) and the testimony of neurosurgeons (Pool, 1958) that ${ }_{0}^{\circ}$ cerebral vasospasm occurs in laboratory animals or and man under a wide variety of circumstances, 은 but its importance has been contended (Picker- ing, 1948). Small arteries of a diameter exceed- oे ing about $400-500 \mu$ have limited but distinct lamellae of smooth muscle in their media and would seem to be capable of constriction: arterioles of a smaller calibre have little or n\& medial muscle and probably do not constrict

At necropsy on a case of subarachnoiâ haemorrhage due to a ruptured anterior cerebral aneurysm, Small and Smith (1964) found fibrinoid necrosis of an aneurysm-bearing artery which had previously shown spastic narrowing on angiography; it therefore appeared probable that the necrosis resulted from vasospasm. Comparable fibrinoid necrosis of cerebral arterioles can follow-on the spasm which is characteristic of experimental hypertensive $\frac{0}{3}$ encephalopathy in rats (Byrom, 1954). Recent $\frac{3}{6}$. investigations by one of us (W.T.S. unpublished $\frac{5}{3}$ data) indicates that vascular necrosis is a rare sequel of subarachnoid bleeding.

The vasospastic stimulus in subarachnoid haemorrhage is conjectural. It could be the reflex effect of aneurysmal rupture or the irri- $\frac{D}{O}$ tative effect of blood or blood-clot, though homolateral vessels some distance from signifi- N cant haematomas, or even contralateral vessels $N$ can show spasm. Large haematomas and sys- $N$ temic hypertension are commonly present $\mathrm{\omega}$ (Allcock and Drake, 1965). Operation certainly seems to bring on spasm in many cases, $\stackrel{0}{\square}$ especially when there is a short period between bleeding and surgery, and when hypothermia, excessive hyperventilation and possibly fluo- $\frac{0}{0}$ thane anaesthesia are used; these findings led $\stackrel{\vec{D}}{\mathrm{D}}$

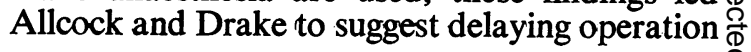


for several weeks if possible. Surgery should be planned to avoid disturbing haematomas and the altered blood vessels traversing them. The adverse effects of angiography are considered by Schneck (1964).

Spasm could also be related to the liberation of chemical substances, such as 5-hydroxytryptamine (5HT; serotonin) from the blood clot. 5HT was shown experimentally to be a cerebral vasoconstrictor by Raynor, MoMurtry and Pool (1961). Honour and Mitchell (1964) found that both human and rabbit red blood cell extracts and 5HT gave rise to platelet clumps ("white bodies") which built up and embolized when applied to minimally injured rabbit cerebral arteries; red cell extracts but not 5HT also caused vasoconstriction; these observations and the possible role of platelet clumping merit further study in relation to subarachnoid haemorrhage. Buckell (1964) demonstrated substances capable of contracting smooth muscle in fluid taken from haematomas resulting from rupture of cerebral aneurysms. If such substances do play a part in the development of spasm, it is conceivable that antagonistic drugs could be used therapeutically. Preliminary experiments along these lines using synthetic antiserotonin agents were not significantly effective (Raynor and MoMurtry, 1963).

There is little doubt that cerebral infarction is the cause of many of the residual clinical disabilities, often profound, that Walton (1956) found in about $70 \%$ of patients surviving subarachnoid haemorrhage due to ruptured aneurysms; larger, focal lesions due to haematomas are much more likely to be immediately lethal.

\section{Massive Hypertensive Cerebral Haemorrhage}

The association of cerebral haemorrhage and high blood pressure has been well-known since Wepfer (1658) first associated strengthening of the pulse with apoplexy, and demonstrated intraventricular clot and destruction of the brain by haemorrhage and since Baglivi (1699), in the necropsy report on Marcellus Malphigi, the Pope's physician and renowned anatomist, described both intraventricular blood in the brain and hypertrophy of the left ventricle of the heart. Though the exact mechanism is still uncertain the massive nature and sudden onset, with rapid rise in intracranial pressure suggests that the haemorrhage is arterial rather than venous or capillary. Various changes have been noticed in the cerebral arteries in such cases, but are not confined to the perforating arteries in the region of the basal nuclei, where bleeding most commonly occurs.

\section{Micro-aneurysms}

In 1868 Charcot and Bouchard made the first significant investigation of cerebral haemorrhage and demonstrated saccular or fusiform miliary, or more correctly submiliary aneurysms on the small cerebral arteries of $250-400 \mu$ diameter. In the adventitia of these vessels they described periarteritic changes, responsible for the aneurysms, rupture of which resulted in the haemorrhage. The aneurysms were demonstrated by immersing the brains in running water for many weeks, until only the vessels were left; the unpleasant smell associated with the procedure discouraged further research along the same lines for many years. Nevertheless, later reports of submiliary aneurysms were occasionally made by workers using other techniques (Green 1930; Matsuoka, 1952). Ellis (1909) however, considered that these lesions were in fact false aneurysms, the result rather than the cause of arterial rupture; this contention has often been quoted in support of their doubtful significance.

Recently Ross-Russell (1963) carried out a careful examination of a series of hypertensive brains, which were injected with a radio-opaque gelatin solution and examined by microradio graphy after fixation. He found aneurysmaF dilatation of $300-900 \mu$ on the small cerebral arteries of $100-300 \mu$ diameter. These aneurysms occurred commonly but not exclusively at the site of branching and were present in 14 out of 15 hypertensive brains and 10 out of 38 of a control normotensive group. The number of aneurysms in each brain varied from 1 to 20 and were most frequent in the putamen, pallidum and thalamus, but also occurred in the caudate nucleus, internal capsule, centrum semiovale and cortical grey-matter. With one exception, the brains showing more than 10 aneurysms belonged to the hypertensive group which were categorized by the presence of a diastolic blood pressure of $110 \mathrm{~mm}$. Hg. or higher. The heart of this exception weighed $450 \mathrm{~g}$. which in the absence of valvular or ischaemic heart disease could be held to indicate systemic hypertension. Histologically, the affected arteries showed marked medial fibrosis and loss of muscle fibres with fraying and reduplication of the single internal elastic lamella. The aneurysms showed a fibrous, nonmuscular wall into which remnants of elastica extended for a short distance. The luminal surface was lined by endothelium or coated with variable amounts of fibrin. Because none of the 
patients in this study were under 50 years of age, final assessment will depend on the findings in the brains of young hypertensive patients, in whom the natural vascular degeneration of ageing can be expected to be minimal.

\section{The role of perivascular necrosis}

Globus and Strauss (1926) and Westphal and Bär (1926) favoured the view previously expressed by Rouchoux (1844) that haemorrhage occurred from rupture of an artery at a site where the supporting tissue had undergone ischaemic softening. They considered that occlusion of one or more cerebral arteries due to either generalised or localised anterial degeneration (Globus and Strauss) or spasm (Westphal and Bär) created a zone of necrosis around the diseased artery, which was the most important factor in the development of hypertensive cerebral haemorrhage.

Globus and Epstein (1953) provided additional evidence supporting this view in a study based both on further data from human cases and on experimental work in dogs and monkeys. They occluded cerebral arteries and were able to demonstrate haemorrhagic areas, resembling massive cerebral haemorrhage in man, which sometimes developed spontaneously but could be produced more frequently by subsequent injection of neosynephrine.

Bruetman, Fields, Crawford, and de Bakey (1963) confirmed these findings with further clinical material. In the course of evaluating corrective surgical treatment in 900 patients with internal carotid artery stenosis or occlusion, they encountered six who developed postoperative cerebral haemorrhage in the affected hemisphere. Though all six patients were hypertensive, they felt that antecedent infarction was of greater significance than the hypertension.

Rosenblath (1918) had previously held a similar view. He noticed that cerebral haemorrhage frequently occurred in patients with renal disease, and considered that the diseased kidneys liberated an autolytic enzyme which caused cerebral softening into which haemorrhage occurred.

\section{Arterial degeneration secondary to hypertension}

Dorothy Russell (1954) found two principal changes in the cerebral vessels in a series of 232 cases of hypertensive cerebral haemorrhage. In benign hypertension the perforating cerebral arteries showed fibrous replacement of the muscle in the media, which could predispose to rupture. In malignant hypertension fibrinoid necrosis of the arterioles was widely distributed throughout the brain, particularly in the pons, and resembled that seen in the arterioles of other organs in malignant hypertension, particularly in the kidney. She suggested that these vascular changes explained the fact that primary pontine haemorrhage occurred more frequently with malignant than benign hypertension, whereas with haemorrhage elsewhere in the brain the reverse was found.

Okinaka and Kameyama (1960) also described fibrinoid necrosis in the cerebral arteries of cases of cerebral haemorrhage, most commonly in patients over the age of 70 years. They found that the incidence of necrosis was directly proportional to the degree of hypertension, and occurred most frequently in the putmen followed by the thalamus, pons and cerebellum. Arteries showing this change sometimes developed submiliary aneurysms.

Hassler (1962) demonstrated defects in the muscle coat in the small intracerebral arteries in hypertension, particularly at the site of branching, and postulated that such defects could rupture without aneurysm formation.

\section{Vascular necrosis induced by spasm}

Byrom (1954 and 1958-59) considered that in hypertension a vasoconstrictor stimulus pro-8 voked spasm of groups of cerebral arteriole and terminal arteries leading to ischaemia of the territory supplied. The effect depended on the severity, duration and extent of the spasm. An acute widespread crisis would cause anoxia of the whole brain and commonly result in acute hypertensive encephalopathy. Less widespread but more lasting crises would give rise to successive "crops" of lesions of three grades, viz. mild and reversible changes, consisting of small zones of increased capillary permeability and focal oedema; small infarcts or haemorrhages; and focal arterial necrosis sometimes resulting in major haemorrhages.

It is relevant at this point to consider the problem of hypertensive encephalopathy, which Oppenheimer and Fishberg (1928) first associated with cerebral vasospasm and "oedema". Byrom (1954) induced hypertensive encephalopathy in rats and observed and filmed spasm of the cerebral arteries during an attack through acrylic windows inserted in the skull. $\mathrm{He}$ also showed increased capillary permeability distal to the site of spasm by noting escape of trypan blue after injecting the dye into the circulation. He also found that the brains of rats killed during an attack of encephalopathy showed a higher water content than a control group. Meyer, Waltz and Gotoh (1960) obtained similar changes in experiments on monkeys. 
Ziegler, Zosa and Zieli (1965) reviewed 43 patients discharged from hospital over a 10 year period with the diagnosis of hypertensive encephalopathy. On retrospective analysis they considered that only three patients had shown the classical clinical picture, formulated by Oppenheimer and Fishberg, of seizures with focal neurological signs and symptoms complicating advanced hypertension. The remainder were classified as uraemia (10 cases), cerebrovascular insufficiency (13 cases), cerebral infarction (10 cases), cerebral and subarachnoid haemorrhage (4 cases), and miscellaneous entities ( 3 cases). These conclusions suggest that classical hypertensive encephalopathy is not to be regarded as a common disorder, at least in recent years.

\section{Cerebral haemorrhage simulating massive hypertensive haemorrhage}

Large intracerebral haematomas secondary to ruptured berry aneurysm on the circle of Willis can simulate hypertensive haemorrhage and have already been considered. Massive haemorrhage due to blood diseases or true neoplasms etc. can also occur but will not be discussed in this review. A comment on cerebral haemorrhage complicating hamartomatous vascular malformations is however appropriate as it has recently been the subject of several reports, and is important from the diagnostic point of view.

Hawkins and Rewell (1946) described two cases of apoplexy in early life which were subsequently shown to be caused by haemorrhage from cavernous haemangiomas. Though haemorrhage into such malformations had been described, previously it had not been associated with apoplexy without previous symptoms (Lindau, 1931; Elkington, 1935). Margolis, Odom, Woodhall, and Bloor (1952) reported four similar cases with spontaneous intracranial haematomas due to small ruptured angiomatous malformations and suggested that many examples of spontaneous cerebral haemorrhages of uncertain aetiology in young people could be of this nature. Dorothy Russell (1954) analysed 461 cases of intracranial haemorrhages, and attributed 21 to vascular hamartomas which she classified as telangiectases, cavernous haemangiomas, and arterio-venous hamarlatter type were subsequently described in detail (Crawford and Dorothy Russell, 1956) and termed "cryptic hamartoma" on account of their latent clinical characters and the difficulty often encountered in locating and demonstrating them. These "cryptic hamartomas" were divided into three groups on an anatomical basis: related to the cerebral convexities (10 tomas. Twenty of the cases associated with the examples); central cerebral (4 examples); and cerebellar (6 examples). Bleeding occurred at a younger age than in classical hypertensive cerebral haemorrhage, all cases being under 40 years, and 15 under 20 years of age. Clinically they showed evidence of catastrophic apoplexy or in less acute cases simulated rapidly growing neoplasms. Krayenbühi and Siebenmann (1961) recently reported a further 24 similar cases of spontaneous cerebral haemorrhage and in 15 they were able to demonstrate vascular malformations on angiography; they assumed that the haemorrhage had destroyed the malformation in the other 9 cases.

\section{Conclusions}

Current views regarding the pathogenesis of hypertensive cerebral haemorrhage are to some extent complementary and all implicate degeneration of small arteries prior to actual rupture. Though the evidence that submiliary aneurysms are frequently present is conclusive, their significance in all cases has not been finally substantiated, as they can certainly develop in normotensive brains without causing haemor rhage. It could be that several factors, eithero alone or in combination, operate in different cases to produce the identical final catastrophe. It is not without interest that aetiological considerations such as age, hypertension and spasm are also relevant to the pathogenesis and complications of cerebral infarction and berry aneurysm. Such inter-relationships should not be overlooked when adjusting this whole group of disorders.

\section{Summary}

Current views on the pathogenesis of cerebral infarction due to atherosclerosis, cerebral berry aneurysms and their complications, and massive hypertensive cerebral haemorrhage are discussed.

Particular attention is directed to the role both of stenosis (and its relation to embolism) and of occlusion of the neck-arteries in infarction, to the cause of berry aneurysms and the complications which can result from their rupture, and to the mechanism of massive cerebral haemorrhage.

Factors such as arterial degeneration, hypertension, vasospasm, age and diet are to a variable extent relevant to the pathogenesis and consequences of all three main types of "stroke". 


\section{REFERENCES}

Abercrombie, J. (1828): Pathological and Practical Researches on Diseases of the Brain and the Spinal Cord. Edinburgh: Waugh and Innes.

AllCOCK, J. M. and DRAKE, C. G. (1965): Ruptured Intracranial Aneurysms - the Role of Anterial Spasm, J. Neurosurg., 22, 21.

Alpers, B. J. and BerRy, R. G. (1963): The Circle of Willis in Cerebrovascular Disorders, Arch. Neurol. (Chic.), 8, 398.

Baglivi, G. (1699): De Praxi Medica ad Verum Observandi Rationem Revocanda, Libro Duo, p. 403. Paris: Joannem Anisson.

BAKER, A. B., DAHL, E. and SANDler, B. (1963): Cerebrovascular Disease. Etiologic Factors in Cerebral Infarction: Neurology (Minneap.), 13, 445.

DU Boulay, G. (1963): Distribution of Spasm in the Intracranial Arteries after Subarachnoid Haemorrhage, Acta radiol (Stockh.), 1, (new series), 257.

Brain, Lord (1963): Some Unsolved Problems of Cervical Spondylosis, Brit. med. J., i, 771.

BrICE, J. G., DowseTt, D. J. and Lowe, R. D. (1965): Haemodynamic Effects of Carotid Artery Stenosis, Brit. med. J., ii, 1363.

Bruetman, M. E., Fields, W. S., Crawford, E. S., DE BAKEY, M. E. (1963): Cerebral Haemorrhage in Carotid Artery Surgery, Arch. Neurol. (Chic.), 9, 458.

BUCKELL, M. (1964): Demonstration of Substances Capable of Contracting Smooth Muscle in the Haematoma Fluid from Certain Cases of Ruptured Cerebral Aneurysm, J. Neurol. Neurosurg. Psychiat, 27, 198.

BYROM, F. B. (1954): Pathogenesis of Hypertensive Encephalopathy and Its Relation to the Malignant Phase of Hypertension, Lancet, ii, 201.

(1958-59): The Significance of Hypertensive Encephalopathy, in Lectures on the Scientific Basis of Medicine, vol. 8, p. 256, University of London: The Athlone Press.

Carmichael, R. (1950): The Pathogenesis of NonInflammatory Cerebral Aneurysms, J. Path. Bact., 62, 1.

CharcotT, J. M. and Bouchard, C. (1868): Novelles Recherches sur la Pathogenie de l'Hemorrhagie Cérébrale, Arch. Physiol. norm. et path., 1, 110, 634 and 275.

CoHNHEIM, J. (1872): Untersuchungen uber die Embolischen Processe. Berlin: Hirschwald.

Corday, E., Rothenburg, S. F. and Irving, D. W. (1963): Cerebral Angiospasm-A Cause of Cerebral Stroke, Amer. J. Cardiol., 11, 66.

Crawford, J. V. and Russell, D. S. (1956): Cryptic Arterio-venous and Venous Hamartomas of the Brain, J. Neurol., Neurosurg. Psychiat., 19, 1.

CraWford, T. (1959): Some Observations on the Pathogenesis and History of Intracranial Aneurysms, J. Neurol. Neurosurg. Psychiat., 22, 259.

Crompton, M. R. (1962): Intracerebral Haematoma Complicating Ruptured Cerebral Berry Aneurysm, J. Neurol. Neurosurg. Psychiat., 25, 378.

- (1964a): Cerebral Infaration Following Rupture of Cerebral Berry Aneurysms, Brain, 87, 263.

(1964b): The Pathogenesis of Cerebral Infarction Following the Rupture of Cerebral Berry Aneurysms, Brain, 87, 491.

DE BAKEY, M. E., CraWford, E. S. and Fields, W. S. (1961): Surgical Treatment of Patients with Cerebral Artery Insufficiency Associated with Ex- tracranial Arterial Occlusive Lesions, Neurology (Minneap.), 11, Supplement p. 145.

DENNY-Brown, D. (1951): The Treatment of Recurrent Cerebrovascular Symptoms and the Question of Vasospasm, Med. Clin. N. Amer., 35, 1457.

DiCKINSON, C. J. (1961): Functional Efficiency of the Circle of Willis, Brit. med. J., i, 858.

VANDER EECKEN, H. M. and ADAMS, R. D. (1953): Anatomy and Functional Significance of Meningeal Arterial Anastomoses of the Human Brain, $J$ Neuropath. exp. Neurol., 12, 132.

ElKingtoN, J. ST. C. (1935): Cerebral Vascular Accidents Unassociated with Cardiovascular Disease, Lancet, i, 6.

Ellis, A. G. (1909): The Pathogenesis of Spontaneous Cerebral Haemorrhage, Proc. path. Soc. Philad., 12 (new series) 3, 197.

Forbus, W. D. (1930): On the Origin of Miliary Aneurysms of the Superficial Cerebral Arteries, Bull. Johns Hopk. Hosp., 47, 239.

Fisher, C. M., Gore, I., OKaBe, N. and White, P. D. (1965): Atherosclerosis of the Carotid and Vertebral Arteries-Extracranial and Intracranial, $J$. Neuropath. exp. Neurol., 24, 455.

Globus, J. H. and Strauss, I. S. (1926): Massive Cerebral Haemorrhage. Its Relation to Pre existing Cerebral Softening. Arch. Neurol. Psychiat. (Chic.), 18, 215.

Globus, J. H. and Epstein, J. A. (1953): Massive Cerebral Haemorrhage: Spontaneous and Experimentally Induced, J. Neuropath. exp. Neurol., 12 , 107.

GlynN, L. E. (1940): Medial Defects in the Circle of Willis and Their Relation to Aneurysm Formas tion, J. Path., Bact., 51, 213.

GreEN, F. H. K. (1930): Miliary Aneurysms in the? Brain, J. Path. Bact., 33, 71.

Gull, W. (1855): Thickening and Dilatation of the Arch of the Aorta, with Occlusion of the Innominata and Left Carotid, Atrophic Softening of the Brain, Guy's Hosp. Rep., ser., 3, 1, 12.

Gunning, A. J., Pickering, G. W., RobB-Smith, A. H. T. and Ross-Russell, R. (1964): Mural Thrombosis of the Internal Carotid Artery and Subsequent Embolism, Quart. J. Med., 33, 155.

Hassler, O. (1962): Medial Defects in Intracerebral Arteries, Acta neurol. scand., 38, 29.

Hawkins, C. F. and Rewell, R. E. (1946): Unheralded Fatal Haemorrhages in Haemangiomata of the Brain, Guy's Hosp. Rep., 95, 88.

Honour, A. J. and Mitchell, J. R. A. (1964): Platelet Clumping in Injured Vessels, Brit. J. exp. Path., 45, 75.

Humphries, A. W., Young, J. R., Beven, E. G., LeFeVRe, FAY, A., and DE Wolfe, V. G. (1965): Relief of Vertebrobasilar Symptoms by Carotid Endarterectomy, Surgery, 57, 48.

Hunt, J. Ramsay (1914): The Role of the Carotid Arteries in the Causation of Vascular Lesions of the Brain, Amer. J. med. Sci., 147, 704.

Hutchinson, E. C. and Yates, P. O. (1957): Carotico-Vertebral Stenosis, Lancet, i, 2.

Hutchinson, E. C. (1962): The Circle of Willis Today, in Modern Trends in Neurology, ed. by Denis Williams, p. 175, London: Butterworths.

Krayenbuhl, H. and SiebenmanN, R. (1965): Small Vascular Malformations Causing Haemorrhage, J. Neurosurg., 12, 7.

LindaU, A. (1931): Discussion on Vascular Tumours of the Brain and Spinal Cord, Proc. roy. Soc. Med., 24, 363. 
McGee, D. A., McPhedran, R. S. and Hoffman, H. J. (1962): Carotid and Vertebral Artery Disease, Neurology (Minneap.), 12, 848.

Margolis, G., ODOM, G. L., WoOdhall, B. and Bloor, B. M. (1951): The Role of Small Angiomatous Malformations in the Production of Intracerebral Hematomas, J. Neurosurg., 8, 564.

Marshall, J. (1964): The Natural History of Transient Ischaemic Cerebrovascular Attacks, Quart. J. Med., 33, 309.

MatsuoKA, S. (1952): Histopathological Studies on the Blood Vessels in Apoplexia Cerebri, Proc. 1st. internat. Cong. Neuropath. (Rome), 3, 222.

MeYer, J. S., Waltz, A. G. and Gotoh, F. (1960): Pathogenesis of Cerebral Vasospasm in Hypertensive Encephalopathy, I and II, Neurology (Minneap). 10, 735 and 859 .

Mitchell, J. R. A. and Schwartz, C. J. (1965): Arterial Disease. Oxford: Blackwell Scientific Publications.

Moniz, E., LimA, A. and DE LACERDA, R. (1937): Hemiplegies par Thrombose de la Carotide Interne, Presse méd., 45, 977.

Morgagni, J. B. (1761): De Sedibus et Causis Morborum. Translation by B. Alexander (1769). London: Millar and Cadell.

MurRAY, J. (1919): ed. of A New English Dictionary, vols. I and IX. Oxford: Clarendon Press.

NothnaGel, C. W. H. (1877): Anaemia, Hyperaemia, Haemorrhage, Thrombosis and Embolism of the Brain, in Cyclopaedia of the Practice of Medicine, ed. by $H$. von Ziemssen, 12, 3. London: Samson Low.

OKinaka, S. and Kameyama, M. (1960): A Study of the Etiology of Hypertensive Cerebral Haemorrhage from the Viewpoint of Vascular Pathology, Trans. Amer. neur. Ass., 85, 114.

OPPENHEIMER, B. S. and FISHBERG, A. M. (1928): Hypertensive Encephalopathy, Arch. intern. Med., 41, 264.

Patel, A. and Toole, J. F. (1965): Subclavian Steal Syndrome-Reversal of Cephalic Blood Flow, Medicine (Baltimore), 44, 289.

Pickering, G. W. (1948): Transient Cerebral Paralysis in Hypertension and in Cerebral Embolism, With Special Reference to the Pathogenesis of Hypertensive Encephalopathy, J. Amer. med. Ass. 137, 423.

Pool, J. M. (1958): Cerebral Vasospasm, New Engl. J. Med., 259, 1259 .

RAYNor, R. B., McMurtry, J. G. and Pool, J. L. (1961): Cerebrovascular Effects of Topically Applied Serotonin in the Cat, Neurology (Minneap.), 11, 190.

RAYNOR, R. B. and MCMurTRY, J. G. (1963): Prevention of Serotonin-Produced Cerebral Vasospasm, J. Neurosurg., $20,1$.

Richardson, J. C. and Hyland, H. H. (1941): Intracranial Aneurysms. A Clinical and Pathological Study of Subarachnoid and Intracerebral Haemorrhage Caused by Berry Aneurysms, Medicine (Baltimore), 20, 1.

RIGGS, Helena E., and RUPP, C. (1963): Variations in Form of the Circle of Willis, Arch. Neurol. (Chic.), $8,8$.

RoB, C. G. (1961): The Surgical Treatment of Stenosis and Thrombosis of the Extracranial Portions of the Carotid Arteries, J. cardiovasc. Surg., 2, 336.

RoBERTS, B. (1965): Carotid-Vertebral Artery Stenosis and Occlusion, Practitioner, 194, 214.
Robertson, E. G. (1949): Cerebral Lesions Due to Intracranial Aneurysms, Brain, 72, 150.

ROSENBLATH, (1918): Ueber die Entstehung der Hirnblutung bei dem Schlaganfall, Dtsch. Z. @ Nervenheilk, 61, 10.

Rouchoux, J. A. (1844): Du Ramollissement de Cerveau et de sa Curabilité, Arch. gén. Méd., 6, 号 265.

Russell, D. S. (1954): The Pathology of Spontaneous Intracranial Haemorrhage, Proc. roy. Soc. Med. 47, 689.

Ross-Russell, R. W. (1963): Observations on Intracerebral Aneurysms, Brain, 86, 425.

SCHNECK, S. A. (1964): On the Relationship Between Ruptured Intracranial Aneurysm and Cerebral Infarction, Neurology (Minneap.), 14, 691.

SMall, J. M. and SMITH, W. T. (1964): Unpublished Communications to the Society of British Neurosurgeons and The British Neuropathological Society.

SMITH, Barbara (1963): Cerebral Pathology in Subarachnoid Haemorrhage, J. Neurol. Neurosurg. Psychiat., 26, 535.

STEHBENS, W. E. (1959): Medial defects of the Cerebral Arteries of Man, J. Path. Bact., 78, 179. (1963a): Cerebral Aneurysm of Animals Other Than Man, J. Path. Bact., 86, 161.

(1963b): Histopathology of Cerebral Aneurysms, Arch. Neurol. (Chic.), 8, 272.

- (1963c): Aneurysms and Anatomical Variations of Cerebral Arteries, Arch. Path. (Chic.), 75, 45.

ToDD, R. B. (1844): Account of a Case of a Dissecting Aneurysm of the Aorta, Innominate, and Right Carotid Arteries, Giving Rise to Suppression of Urine and White Softening of the Brain, Med chir. Trans., 27, 301.

Tombinson, B. E. (1959): Brain Changes in Ruptures Intracranial Aneurysm, J. clin. Path., 12, 391.

ToOLE, J. F. (1964): Reversed Vertebral Artery Flow and Cerebral Vascular Insufficiency, Ann. intern. Med., 61, 159.

TuRnBull, I. (1962): Agenesis of the Internal Carotid Artery, Neurology (Minneap.), 12, 588.

Walton, J. N. (1956): Subarachnoid Haemorrhage, p. 175. Edinburgh: E. \& S. Livingstone.

WEISS, S. (1938): The Regulation and Disturbance of the Cerebral Circulation Through Extracerebral Mechanisms, Res. Publ. Ass. nerv. ment. Dis., 18 , 571.

WEPFER, J. J. (1658): Historiae Apoplecticorum, Observationibus et Scholiis Anatomicis et Medicis Quanplurimis Elaboratae et Illustratae. Amsterdam: Janssonio-Waesbergios (Published posthumously, 1704).

WestPHAL, K., and BAR, R. (1926): Ueber die Entstehung des Schlaganfalles. I Pathologisch-anatomische Untersuchhungen zur Frage der Entstehung des Schleganfalles, Dtsch. Arch. klin. Med., 151, 1

WilliaMS, D. (1964): Vertebro-basilar Ischaemia, Brit. med. J., i, 84.

Wilson, C. and BYrom, F. B. (1939): Renal Changes in Malignant Hypertension, Lancet, i, 136.

YATES, P. O. and HUTCHINSON, E. C. (1961): Cerebral Infarction: The Role of Stenosis of the Extracranial Cerebral Arteries, Spec. Rep. Ser. med. Res. Coun. (Lond.), No. 300.

YATES, P. O. (1964): A Change in the Pattern of Cerebrovascular Disease, Lancet, i, 65.

ZIEGLER, D. K., ZosA, A., and Zieli, T. (1965): Hypertensive Encephalopathy, Arch. Neurol. (Chic.), 12, 472. 